\title{
Nitridation of Silicon-Dioxide Films Grown on 6H Silicon Carbide
}

\author{
Sima Dimitrijev, Member, IEEE, Hui-feng Li, Student Member, IEEE, H. Barry Harrison, and Denis Sweatman
}

\begin{abstract}
This letter addresses the question of why it is possible to grow high-quality oxide films on N-type but not on P-type SiC. It provides results which indicate that the oxide/SiC interface would be inferior to the oxide/Si interface for both, $\mathrm{N}$-type and P-type SiC, if it were not for the beneficial effects of nitrogen incorporation. The letter presents, for the first time, results on nitridation of thermally grown oxides in $\mathrm{NO}$ and $\mathrm{N}_{2} \mathrm{O}$. The results demonstrate that the oxides grown on P-type can be improved by NO annealing, but not by $\mathrm{N}_{2} \mathrm{O}$ annealing.
\end{abstract}

\section{INTRODUCTION}

$\mathbf{S}$ UCCESSFUL growth of silicon-dioxide films on siliconcarbide substrates may mark the beginning of a new era in semiconductor electronics. Metal-oxide-semiconductor (MOS) devices based on a wide band-gap material such as silicon carbide have the potential to revolutionize power electronics, microwave systems, high temperature, and many other applications.

At present, it is not understood why it is possible to grow high-quality oxide films on N-type but not on P-type $\mathrm{SiC}$ [1]-[6]. Initially, it was speculated that the aluminum (used as the P-type dopant in $\mathrm{SiC}$ ) was causing this problem [2]-[4]. Later, it has been shown that boron-doped P-type SiC does not improve the quality of the oxide [5], and that aluminum is also present in high-quality oxides grown on N-type $\mathrm{SiC}$ [6].

In this letter, we present results which shift the focus from the potential problems with the P-type $\mathrm{SiC}$ to the beneficial role of nitrogen, used as a dopant in the $\mathrm{N}$-type $\mathrm{SiC}$. We report, for the first time, results on nitridation of $\mathrm{O}_{2}$-grown oxides in $\mathrm{NO}$ and $\mathrm{N}_{2} \mathrm{O}$. The results suggest that the oxides grown on P-type $\mathrm{SiC}$ can be improved by $\mathrm{NO}$ annealing, which is a significant step toward a successful fabrication of enhancement type N-channel MOSFET's on SiC.

\section{EXPERIMENTAL DETAILS}

Si-faced $6 \mathrm{H}$ SiC wafers, manufactured by CREE Research, were used in this experiment. The concentration of the nitrogen doped N-type wafer was $4.8 \times 10^{17} \mathrm{~cm}^{-3}$, while the concentration of the aluminum doped P-type wafer was $2.5 \times 10^{18}$ $\mathrm{cm}^{-3}$. The wafers were cut into approximately $1.5 \times 1.5 \mathrm{~cm}$ pieces, and cleaned by both an $\mathrm{H}_{2} \mathrm{SO}_{4}: \mathrm{H}_{2} \mathrm{O}_{2}$ solution and RCA cleaning process. Immediately before the oxidation, the samples were dipped in $1 \% \mathrm{HF}$ for $60 \mathrm{~s}$. The $\mathrm{SiC}$ carbide

Manuscript received November 29, 1996. This work was supported by a Large Australian Research Council (ARC) Grant.

The authors are with School of Microelectronic Engineering, Griffith University, Nathan, Brisbane, Queensland 4111, Australia.

Publisher Item Identifier S 0741-3106(97)03493-9. pieces were placed onto a 6-in silicon wafer, to perform the oxidation in an AG610 rapid-thermal processing (RTP) unit. The oxidation was performed in six 5-min. steps (to allow cooling of the RTP unit) in high-purity $\mathrm{O}_{2}$ at around $1100{ }^{\circ} \mathrm{C}$. After the oxidation, two sets of samples received an additional 5-min treatment at the same temperature: one set of samples was exposed to a $99 \%$ (chemical pure grade) NO, while the other was exposed to a high-purity $\mathrm{N}_{2} \mathrm{O}$ environment. Following the oxidation and the nitridation of the samples, aluminum was evaporated at the top and the back of the samples, and circular 300- $\mu \mathrm{m}$ dots defined at the top by a photolithography process to create MOS capacitors. No postmetal annealing is performed, to avoid masking the defects created during the oxidation and/or nitridation. MOS capacitor characterization was performed by high-frequency $(100 \mathrm{kHz}$ capacitance-voltage $(C-V)$ and conductance-voltage measurements, using a computer-controlled HP4284A LCR meter.

\section{Si BACKGRound, SiC Results, AND Discussion}

The increasing demand for thinner and better gate dielectrics in silicon technology motivates extensive investigations into potential benefits of nitridation of oxide films grown on $\mathrm{Si}$. Annealing in $\mathrm{NO}$ and $\mathrm{N}_{2} \mathrm{O}$ appear to be the two most promising techniques. While both techniques lead to incorporation of nitrogen at the interface, the annealing in $\mathrm{N}_{2} \mathrm{O}$ leads to new oxide growth [7], as opposed to the annealing in NO which nitrides the interface with virtually no new oxide growth [8]-[11]. The nitrogen accumulation at the interface is related to observed improvements of the electrical characteristics of oxide/silicon interface [8]-[14]. Similar effects have been observed when the oxide is grown on nitrogen implanted polysilicon [15].

It is indicative to correlate these silicon-related results to the results of Palmour et al. [16], showing a similar accumulation of nitrogen at the oxide/silicon-carbide interface during thermal oxidation of nitrogen-doped N-type $\mathrm{SiC}$ substrate. This leads us to a hypothesis that the nitrogen incorporation improves the oxide/N-type silicon-carbide interface, which would otherwise remain inferior compared to the oxide/silicon interface. Furthermore, this suggests that the quality of oxides grown on P-type $\mathrm{SiC}$ could be improved by an appropriate nitridation process.

De Meo et al. [17] showed that oxides on $\mathrm{SiC}$ substrate can directly be grown in $\mathrm{N}_{2} \mathrm{O}$ rather than $\mathrm{O}_{2}$ or $\mathrm{H}_{2} \mathrm{O}$. However, they could not demonstrate an improvement in the interface characteristics of $\mathrm{N}_{2} \mathrm{O}$ grown oxides on $\mathrm{N}$-type $\mathrm{SiC}$. Having observed a number of differences in the effects of $\mathrm{NO}$ and $\mathrm{N}_{2} \mathrm{O}$ 


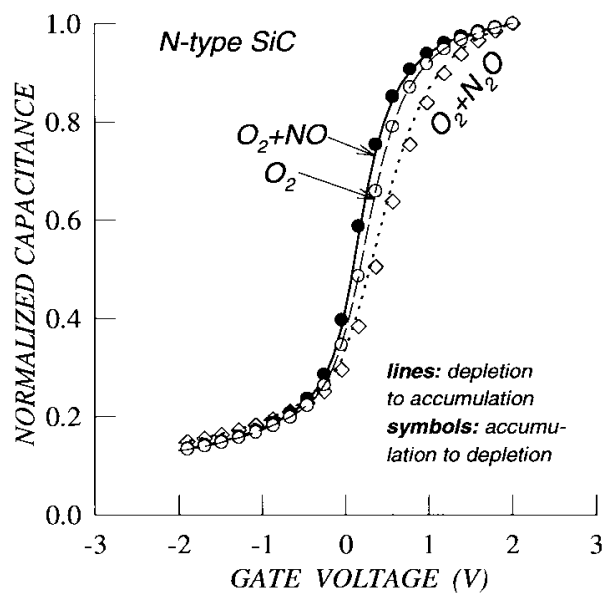

Fig. 1. High-frequency (100 kHz) $C-V$ measurements of MOS capacitors created on N-type $6 \mathrm{H} \mathrm{SiC}$.

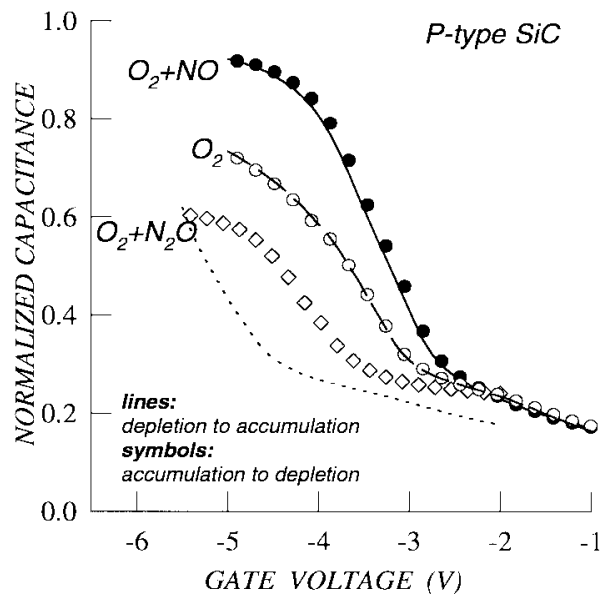

Fig. 2. High-frequency (100 kHz) $C-V$ measurements of MOS capacitors created on P-type $6 \mathrm{H} \mathrm{SiC}$.

on oxides grown on $\mathrm{Si}$ [9], [18], [19], we decided to anneal oxides grown on $\mathrm{SiC}$ in both $\mathrm{NO}$ and $\mathrm{N}_{2} \mathrm{O}$ atmosphere. We also included the both $\mathrm{N}$-type and $\mathrm{P}$-type $\mathrm{SiC}$ substrates. The main results are presented in Figs. 1 and 2, and Table I.

The oxide thicknesses, shown in Table I, were calculated from the accumulation capacitances of the $\mathrm{N}$-type samples, and assumed to be the same for the corresponding P-type samples. Direct calculations of the oxide thicknesses on Ptype samples would not be meaningful as the $C-V$ curves of P-type samples do not saturate at negative voltages. The HF $C-V$ curves are normalized accordingly, and shown for the both sweeping directions. To calculate the work-function differences $\left(\phi_{\mathrm{ms}}\right)$ shown in Table I, the following parameters are used: the work-function of aluminum $\phi_{m}=4.1 \mathrm{eV}$ [20], the silicon-carbide electron affinity $q \chi=3.85 \mathrm{eV}$ [21], and the intrinsic carrier concentration of $6 \mathrm{H} \mathrm{SiC} n_{i}=1.6 \times 10^{-6}$ $\mathrm{cm}^{-3}$ [22]. The flat-band voltages were determined from the flat-band capacitances, calculated by the standard expression [23]. The oxide-charge densities were calculated as $Q_{\mathrm{ox}}=$ $-C_{\mathrm{ox}}\left(V_{F B}-\phi_{\mathrm{ms}}\right) / q$. The interface-trap densities $D_{\mathrm{it}}$ were determined using the conductance technique [24].
TABLE I

EFFects of NO AND $\mathrm{N}_{2} \mathrm{O}$ AnNEALing on the Oxide ChaRge AND INTERFACE TRAP DENSITY OF MOS CAPACITORS CREATED ON 6H SiC

\begin{tabular}{|c|c|c|c|}
\hline & $\mathrm{O}_{2}$ & $\mathrm{O}_{2}+\mathrm{NO}$ & $\mathrm{O}_{2}+\mathrm{N}_{2} \mathrm{O}$ \\
\hline & \multicolumn{3}{|c|}{ N-type $\left(\phi_{m s}=0.15 V\right)$} \\
\hline$t_{o x}[n m]$ & 3.5 & 3.5 & 3.9 \\
\hline$C_{F B} / C_{O x}$ & 0.62 & 0.62 & 0.65 \\
\hline$V_{F B}[V]$ & 0.3 & 0.2 & 0.5 \\
\hline$Q_{o x}\left(@ V_{F B}\right)$ & & & \\
\hline$\times 10^{12} \mathrm{~cm}^{-2}$ & -0.9 & -0.3 & -1.9 \\
\hline \multirow{3}{*}{$\begin{array}{c}D_{i t-\max } \\
\times 10^{11} \mathrm{~cm}^{-2} \mathrm{eV}^{-1}\end{array}$} & & & \\
\hline & 1.1 & 0.3 & 1.3 \\
\hline & \multicolumn{3}{|c|}{ P-type $\left(\phi_{m s}=-2.70 \mathrm{~V}\right)$} \\
\hline$t_{o x}[n m]$ & 3.5 & 3.5 & 3.9 \\
\hline$C_{F B} / C_{O x}$ & 0.79 & 0.79 & 0.81 \\
\hline$V_{F B}[V]$ & $<-5.0$ & -3.9 & $<-5.5$ \\
\hline$Q_{a x}\left(@ V_{F B}\right)$ & & & \\
\hline$\times 10^{12} \mathrm{~cm}^{-2}$ & $>14$ & 7.3 & $>15$ \\
\hline
\end{tabular}

Analyzing the presented results, the following two observations are made: 1) the effects of annealing in either $\mathrm{NO}$ or $\mathrm{N}_{2} \mathrm{O}$ are much more pronounced in aluminum-doped (P-type) $\mathrm{SiC}$ samples, compared to nitrogen-doped (N-type) $\mathrm{SiC}$ samples, 2) $\mathrm{NO}$ annealing improves, while $\mathrm{N}_{2} \mathrm{O}$ annealing deteriorates the electrical characteristics of thermally grown oxides on either $\mathrm{P}$ - or N-type SiC substrate.

The first point directly supports the hypothesis on the beneficial role of nitrogen, as the stability of the oxides grown on the nitrogen-doped $\mathrm{SiC}$ substrates can be explained by the nitrogen present at the interface before any nitridation treatment was applied. As opposed to the relative stability of N-type samples, the electrical characteristics of the oxides grown on P-type substrates were significantly improved by the $\mathrm{NO}$ annealing. The $C-V$ curve of the NO-annealed sampled almost reaches the accumulation value observed on the $\mathrm{N}$ type samples. It is much closer to the ideal $C-V$ curve than the $C-V$ curve of $\mathrm{O}_{2}$ (not-nitrided) sample, which shows the problems observed by other researchers [1]-[6]. It appears the presence of a significant amount of interface traps causes such a stretch that the $C-V$ curve cannot reach the accumulation capacitance up to $-5 \mathrm{~V}$, which is the breakdown voltage.

The results clearly demonstrate a deterioration of the interface characteristics during the $\mathrm{N}_{2} \mathrm{O}$ annealing. Again, this is especially pronounced for the P-type samples. Different $C-V$ curves appear for the different sweep directions during the measurements, indicating that the equilibrium cannot be achieved due to the action of slow traps. In addition, a negative voltage shift is obvious, indicating the presence of a significant amount of positive charge in the oxide or at the interface with $\mathrm{SiC}$. We believe it would be very interesting to study these effects of $\mathrm{N}_{2} \mathrm{O}$ annealing, as it may help to understand better 
the nitridation of thermally grown oxides not only on $\mathrm{SiC}$, but also on Si substrates.

\section{CONCLUSIONS}

In conclusion, we presented results on $\mathrm{NO}$ and $\mathrm{N}_{2} \mathrm{O}$ annealing of oxides grown on $\mathrm{N}$-type and P-type $6 \mathrm{H}-\mathrm{SiC}$ substrates. The results show that the annealing significantly affected the P-type oxides, while the effects in N-type oxides were marginal. This indicates that a stable nitrided interface is created during the oxidation in the case of nitrogen-doped $\mathrm{N}$ type $\mathrm{SiC}$ substrates. It is also demonstrated that the oxides grown on P-type can be improved by NO annealing, but not by $\mathrm{N}_{2} \mathrm{O}$ annealing.

\section{REFERENCES}

[1] T. Ouisse, N. Becourt, C. Jaussaud, and F. Tempiler, "Low-frequency, high-temperature conductance and capacitance measurements on metaloxide-silicon carbide capacitors," J. Appl. Phys., vol. 75, pp. 604-607, 1994.

[2] C. Raynaud, J.-L. Autran, B. Balland, G. Guillot, C. Jaussaud, and T. Billon, "Electrical characterization of instabilities in $6 \mathrm{H}$ silicon carbide metal-oxide-semiconductor capacitors," J. Appl. Phys., vol. 76, pp. 993-997, 1994.

[3] D. Alok, P. K. McLarty, and B. J. Baliga, "Electrical properties of thermal oxide grown using dry oxidation on P-type $6 \mathrm{H}$-silicon carbide," Appl. Phys. Lett., vol. 65, pp. 2177-2178, 1994.

[4] D. M. Brown, M. Ghezzo, J. Kretchmer, E. Downey, J. Pimbley, and J. Palmour, "SiC MOS interface characteristics," IEEE Trans. Electron Devices, vol. 41, pp. 618-620, 1994.

[5] J. N. Shenoy, G. L. Chindalore, M. R. Melloch, J. A. Cooper, Jr., J. W. Palmour, and K. G. Irvine, "Characterization and optimization of the $\mathrm{SiO}_{2} / \mathrm{SiC}$ metal-oxide semiconductor interface," J. Electron. Mater., vol. 24, pp. 303-309, 1995.

[6] S. Sridevan, P. K. McLarty, and B. J. Baliga, "On the presence of aluminum in thermally grown oxides on $6 \mathrm{H}$-silicon carbide," IEEE Electron Device Lett., vol. 17, pp. 136-138, 1996.

[7] S. Dimitrijev, H. B. Harrison, and D. Sweatman, "Extension of the dealgrove oxidation model to include the effects of nitrogen," IEEE Trans. Elecron. Devices, vol. 43, pp. 267-272, 1996.

[8] Y. Okada, P. J. Tobin, K. G. Reid, R. I. Hedge, B. Maiti, and S. A. Ajuria, "Furnace grown gate oxynitride using nitric oxide (NO)," IEEE Trans. Electron Devices, vol. 41, pp. 1608-1613, 1994.
[9] Z.-Q. Yao, H. B. Harrison, S. Dimitrijev, and Y.-T. Yeow, "Effects of nitric oxide annealing of thermally grown silicon dioxide characteristics," IEEE Electron Device Lett., vol. 16, pp. 345-347, 1995.

[10] M. Bhat, D. J. Wristers, L.-K. Han, J. Yan, H. J. Fulford, and D.L. Kwong, "Electrical properties and reliability of MOSFET's with rapid thermal NO-nitrided $\mathrm{SiO}_{2}$ gate dielectrics," IEEE Trans. Electron Devices, vol. 42, pp. 907-914, 1995.

[11] M. Bhat, J. Kim, J. Yan, G. W. Yoon, L. K. Han, and D. L. Kwong, "MOS characteristics of ultrathin NO-grown oxynitrides," IEEE Electron Device Lett., vol. 15, pp. 421-423, 1994.

[12] A. Uchiyama, H. Fukuda, T. Hayashi, T. Iwabuchi, and S. Ohno, "Highperformance $\mathrm{P}^{+}$-gate $\mathrm{P}$ MOSFET's with $\mathrm{N}_{2} \mathrm{O}$ nitrided $\mathrm{SiO}_{2}$ gate films," Electron. Lett., vol. 26, p. 1932, 1990.

[13] H. Fukuda, T. Arakawa, and S. Ohno, "Highly reliable thin nitrided $\mathrm{SiO}_{2}$ films formed by rapid thermal processing in $\mathrm{N}_{2} \mathrm{O}$ ambient," Electron. Lett., vol. 26, p. 1505, 1990.

[14] Z. Liu, H.-J. Wann, P. K. Ko, C. Hu, and Y. C. Cheng, "Effects of $\mathrm{N}_{2} \mathrm{O}$ anneal and reoxidation on thermal oxide characteristics," IEEE Electron Device Lett., vol. 13, p. 402, 1992.

[15] C. K. Yang, T. F. Lei, and C. L. Lee, "Characteristics of top-gate thin-film transistors fabricated on nitrogen-implanted polysilicon films," IEEE Trans. Electron Devices, vol. 42, pp. 2163-2169, 1995.

[16] J. W. Palmour, R. F. Davis, H. S. Kong, S. F. Corcoran, and D. P. Griffis, "Dopant redistribution during thermal oxidation of monocrystalline betaSiC thin films," J. Electrochem. Soc., vol. 136, pp. 502-507, 1989.

[17] R. C. De Mao, T. K. Wang, T. P. Chow, D. M. Brown, and L. G. Matus, "Thermal oxidation of $\mathrm{SiC}$ in $\mathrm{N}_{2} \mathrm{O}$," J. Electrochem. Soc., vol. 141, pp. L150-L152, 1994

[18] Z.-Q. Yao, H. B. Harrison, S. Dimitrijev, D. Sweatman, and Y.-T. Yeow, "High-quality ultrathin dielectric films grown on silicon in a nitric oxide ambient," Appl. Phys. Lett., vol. 64, pp. 3584-3586, 1994.

[19] Z.-Q. Yao, H. B. Harrison, S. Dimitrijev, and Y.-T. Yeow, "The electrical properties of sub-5 $\mathrm{nm}$ oxynitride dielectrics prepared in a nitric oxide ambient using rapid thermal processing," IEEE Electron Device Lett., vol. 15, pp. 516-518, 1994.

[20] R. S. Muller, T. I. Kamins, Device Electronics for Integrated Circuits, 2nd ed. New York: Wiley, 1986, p. 380.

[21] V. V. Afanas'ev, M. Bassler, G. Pensi, and M. J. Shulz, "Band offsets and electronic structure of $\mathrm{SiC} / \mathrm{SiO}_{2}$ interfaces," J. Appl. Phys., vol. 79, pp. 3108-3114, 1996.

[22] M. Ruff, H. Mitlehner, and R. Helbig, "SiC devices: Physics and numerical simulation," IEEE Trans. Electron Devices, vol. 41, pp. 1040-1054, 1994.

[23] S. M. Sze, Physics of Semiconductor Devices, 2nd ed. New York: Wiley, 1981, p. 372.

[24] D. K. Schroder, Semiconductor Materials and Device Characterization. New York: Wiley, 1990. 